\title{
Microclima e Conforto Térmico de um Fragmento de Floresta Urbana em Curitiba, PR
}

\author{
Angeline Martini ${ }^{1}$, Daniela Biondi ${ }^{1}$ \\ ${ }^{1}$ Departamento de Ciências Florestais, Universidade Federal do Paraná - UFPR, Curitiba/PR, Brasil
}

\begin{abstract}
RESUMO
O objetivo deste trabalho foi comparar o microclima e conforto térmico proporcionado por um fragmento de floresta urbana existente no Campus III da UFPR com outros ambientes: gramado, estacionamento e bosque de pinus. Para isso foram coletados dados meteorológicos nas quatro estações do ano. Os resultados encontrados mostram que os demais ambientes estudados são estatisticamente distintos do fragmento de floresta urbana, pois apresentaram maiores valores de temperatura do $\operatorname{ar}\left(3,5^{\circ} \mathrm{C}\right.$ em média) e menores valores de umidade relativa (em média $\left.16 \%\right)$. $\mathrm{O}$ bosque de pinus apresentou a mesma classe de conforto térmico que o fragmento de floresta urbana em todas as estações, predominando a classe "sem estresse". Os resultados demonstram a importância da cobertura arbórea, pois tanto o fragmento florestal como o bosque de pinus apresentam microclimas mais agradável e confortável termicamente do que os ambientes gramado e estacionamento.
\end{abstract}

Palavras-chaves: estresse térmico, uso e ocupação do solo, condições climáticas.

\section{Microclimate and Thermal Comfort of an Urban Forest Fragment in Curitiba, Parana State, Brazil}

\begin{abstract}
The aim of this research was to compare the microclimate and thermal comfort provided by an urban forest fragment with other environments in the Campus III of the Federal University of Parana - UFPR: lawn, parking lot, and pine grove. To this end, meteorological data were collected in the four seasons. The results indicated that the urban forest fragment was statistically different from the other environments, which showed higher values of air temperature (mean of $3.5^{\circ} \mathrm{C}$ ) and lower values of relative humidity (mean of 16\%). In all seasons, the pine grove showed the same category of thermal comfort of the urban forest fragment, with predominance of the "no stress" class. The results emphasize the importance of tree cover, because both the forest fragment and the pine grove provide more thermally comfortable microclimates than the other environments: lawn and parking lot.
\end{abstract}

Keywords: thermal stress, land use and occupation, climate conditions. 


\section{INTRODUÇÃO}

O processo de urbanização provoca alterações significativas no ambiente natural, onde grandes áreas constituídas de vegetação nativa são substituídas por materiais e equipamentos urbanos (Gheno et al., 2012), tais como: asfalto, calçadas, postes e construções das mais variadas formas. Com isso, passaram a existir pequenas áreas de vegetação, fragmentadas dos ambientes originais.

O processo global de fragmentação de habitats é a mais profunda alteração causada pelo homem ao meio ambiente. Muitos habitats naturais que eram contínuos foram transformados em paisagens semelhantes a um mosaico, composto por manchas isoladas de habitat original (Reis \& Conceição, 2010).

Fragmentos florestais urbanos, apesar de sofrerem ação antrópica e de não terem possibilidade de conexão com outras matas, desempenham forte função social, que pode estar relacionada às condições microclimáticas e aos seus aspectos físicos, possibilitando uma diversidade de funções (Dacanal et al., 2010). Dentre estas funções, destacam-se a melhoria microclimática, a amenização acústica, atuação como filtros de partículas que poluem o ar, proteção do solo e sobrevivência da avifauna (Biondi, 2008). Sabe-se que a presença da vegetação nas cidades é essencial para estrutura e dinâmica da paisagem urbana, pois devido às suas características, melhoram a qualidade de vida da população e condição ambiental das cidades (Lima, 2011).

As superfícies vegetadas contribuem para amenizar as condições climáticas, enquanto áreas densamente construídas favorecem a retenção do calor devido à grande concentração de construções e materiais urbanos (França, 2012). Por isso, nas cidades é possível perceber que as áreas densamente construídas apresentam temperaturas mais elevadas quando comparadas ao seu entorno, criando o fenômeno Ilhas de Calor Urbano - ICU (Leal, 2012). Esse fenômeno exerce grande influência na qualidade de vida da população.

Segundo Lombardo (1985), as ilhas de calor urbano correspondem a uma área na qual a temperatura da superfície é mais elevada que as áreas vizinhas, o que propicia o surgimento de circulação local. O efeito da ICU sobre as cidades ocorre devido à redução da evaporação, ao aumento da rugosidade aerodinâmica e às propriedades térmicas dos edifícios e materiais pavimentados. Já Amorim (2010) afirma que este fenômeno está diretamente ligado ao conforto e à saúde dos indivíduos, seja por problemas relacionados ao calor, como o estresse térmico, ou por problemas de doenças relacionados à qualidade do ar.

Essas variações microclimáticas estão fortemente relacionadas ao uso e ocupação do solo, pois a impermeabilização do solo, as construções, a ausência de áreas verdes, o excesso de pavimentação e grande fluxo de veículos e pessoas estão contribuindo para a retenção de calor e redução de umidade do ar, ocasionando uma situação ambiental desconfortável para aqueles que habitam ou circulam nessas áreas (Gheno et al., 2012). Por isso, tornam-se necessários os estudos sobre clima urbano, uma vez que o ser humano sempre está em busca de melhor qualidade de vida e conforto ambiental (Cruz, 2009).

Os campi universitários são excelentes opções para a realização de pesquisas na área da Climatologia Urbana, uma vez que apresentam todas as características físicas e estruturais de uma cidade em uma escala menor (Leal et al., 2009), o que facilita a determinação de ações que promovem o conforto térmico. Biondi (2008) afirma que os ambientes de ensino devem investir no tratamento paisagístico dos seus pátios e espaços livres. Essas áreas quando bem planejadas podem se tornar uma expansão das salas de aula ou um recurso educacional para as práticas de ensino e aprendizagem. Além disso, um tratamento paisagístico da área externa não só melhora as condições das mesmas como também beneficia as salas de aula, proporcionando um maior conforto ambiental.

Se considerar que o conforto térmico e o meio ambiente interferem no aproveitamento didático dos alunos em sala de aula, torna-se importante fazer avaliação do ambiente construído, com a necessidade de investigação para melhorar a qualidade ambiental final do espaço arquitetônico (Beltrame \& Moura, 2011). Assim, pesquisas sobre conforto térmico podem servir como subsídio para o planejamento e ordenamento territorial das instituições de ensino.

Nesse contexto, o objetivo deste trabalho foi comparar o microclima e conforto térmico proporcionado por um fragmento de floresta urbana existente no Campus III -Jardim Botânico da Universidade Federal do Paraná com outros ambientes frequentemente utilizados pelos estudantes, baseado no índice de conforto térmico no período de 2011-2012. 


\section{MATERIAL E MÉTODOS}

A área de estudo é o Campus III da Universidade Federal do Paraná (UFPR), localizado no bairro Jardim Botânico, na cidade de Curitiba. Aproximadamente a $900 \mathrm{~m}$ de altitude, $25^{\circ} 27^{\prime} 12^{\prime \prime} \mathrm{S}$ e $49^{\circ} 14^{\prime} 24^{\prime \prime} \mathrm{W}$. Baseado na classificação de Köppen, a cidade possui o tipo "Cfb", subtropical úmido, mesotérmico, sem estação seca, com verões amenos e invernos com geadas frequentes (IPPUC, 2011).

Os dados mais recentes do IPPUC (2013), entre os anos de 1998 e 2010, mostram temperatura média de $17,8^{\circ} \mathrm{C}$, com variação média de $13,4^{\circ} \mathrm{C}$ no mês mais frio (julho), até $21,8^{\circ} \mathrm{C}$ no mês mais quente (fevereiro). A precipitação pluvial anual média foi de 1403,30 mm e a umidade relativa de $79,4 \%$.

Originalmente a região de Curitiba era coberta por dois tipos de ecossistemas: Estepe Gramíneo-Lenhosa e Floresta Ombrófila Mista, também conhecida como Floresta de Araucária (Roderjan et al., 2002). O Campus III da UFPR possui um dos fragmentos de Floresta Ombrófila Mista existentes em Curitiba conhecido como Capão do Tigre ou Capão da Engenharia Florestal. Possui uma área estimada em 15,24 ha, com relevo suave ondulado e a existência de solos hidromórficos próximos aos canais de drenagem e de Cambissolos e Podzólicos nas regiões mais drenadas (Rondon et al., 2002).
Para o desenvolvimento da pesquisa foram selecionados os seguintes ambientes: área aberta com gramado, estacionamento e interior de um bosque de pinus (Figura 1).

Todas essas áreas estão próximas umas das outras e apresentam características e dimensões variadas. $\mathrm{O}$ equipamento meteorológico foi mantido no centro dessas áreas, sem sofrer influência de elementos diferentes ao que se estava analisando. A área aberta com gramado apresenta em média $2.480 \mathrm{~m}^{2}$, do local onde se instalou o equipamento até um raio de $30 \mathrm{~m}$ para todas as direções não há nada além de gramado. A área de estacionamento compreende $13.500 \mathrm{~m}^{2}$, é revestida com asfalto e durante as coletas de dados apresentava lotação máxima de automóveis; esta característica se manteve em um raio de $30 \mathrm{~m}$ em todas as direções de onde o equipamento foi instalado. $\mathrm{O}$ bosque de pinus apresenta em média $6.850 \mathrm{~m}^{2}$, contém aproximadamente 700 árvores de Pinus taeda, com 10 anos, em um raio de $30 \mathrm{~m}$ de onde foi instalado o equipamento não há outro elemento além de árvores.

O conforto térmico proporcionado por esses ambientes foi analisado por meio do Universal Thermal Climate Index (UTCI), índice desenvolvido pela Sociedade Internacional de Biometeorologia, no ano de 2000 (ISB, 2003). As variáveis meteorológicas necessárias para o cálculo desse índice foram obtidas por meio de dois medidores de estresse térmico, modelo TGD-400. Esses
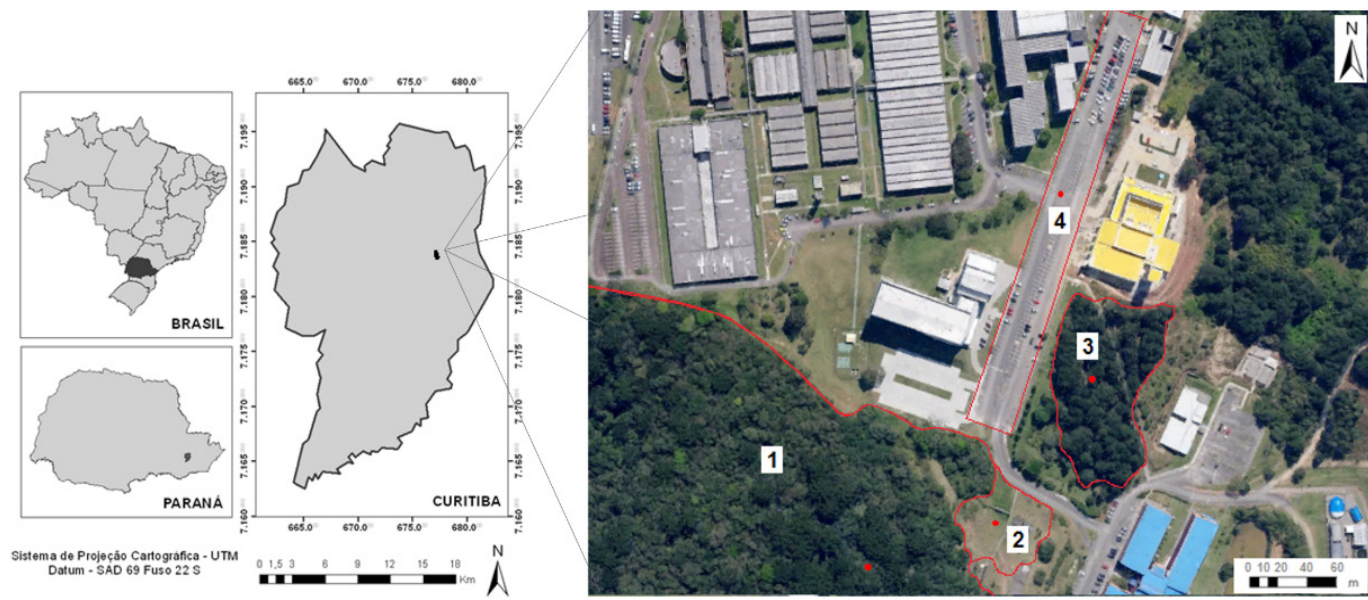

Figura 1. Localização da área de estudo com imagem digital do satélite GeoEye dos ambientes analisados, datada de janeiro de 2009. 1) Fragmento de floresta urbana; 2) Área aberta com gramado; 3) Interior de um bosque de pinus; 4) Estacionamento; os pontos em vermelho referem-se aos locais onde os equipamentos foram instalados.

Figure 1. Location of the study area with digital image the GeoEye of analyzed environments, dated January 2009. 1) Fragment of urban forest; 2) area with lawn; 3) within a pine grove; 4) parking; The red dots refer to the places where the equipment was installed. 
aparelhos foram fixados em um tripé, onde a mesa de sensores permaneceu a 1,50 $\mathrm{m}$ de altura. A abertura da ventilação, de ambos os aparelhos, foi direcionada para a posição Nordeste (NE), na direção predominante.

O monitoramento das variáveis meteorológicas para cada ambiente foi realizado em dias diferentes, devido ao número limitado de equipamentos disponíveis. Dessa forma, em cada dia de coleta, um equipamento permaneceu no interior do fragmento florestal e o outro em um dos ambientes selecionados, sendo necessários quatro dias para a realização das atividades. Esse procedimento também foi repetido nas quatro estações do ano para melhor caracterizar os resultados.

As variáveis meteorológicas utilizadas neste estudo foram: temperatura do ar $\left(\mathrm{T}_{\mathrm{ar}},{ }^{\circ} \mathrm{C}\right)$, umidade relativa (UR, \%), velocidade do vento ( $\mathrm{Vv}, \mathrm{m} / \mathrm{s}$ ) e temperatura do globo $\left(\mathrm{T}_{\mathrm{g}},{ }^{\circ} \mathrm{C}\right)$. O monitoramento foi iniciado na primavera/2011 e encerrou no inverno/2012, sendo que o período de coleta dos dados foi das 11 às $13 \mathrm{~h}$ (horário de Brasília), sendo corrigido para 12 às $14 \mathrm{~h}$ no horário de verão, com intervalo de monitoramento de 1 minuto, o que gerou um conjunto de 120 amostras.

O UTCI foi calculado a cada minuto, por meio do programa Bioklima 2.6, software de livre acesso desenvolvido por Michael Blazejczyk (IGPZ, 2012). Os dados de entrada foram: $\mathrm{Vv}$ a $1,5 \mathrm{~m}$ e a $10 \mathrm{~m}$ de altura do solo, $\mathrm{T}_{\mathrm{ar}}$, UR e temperatura radiante média $\left(\mathrm{T}_{\mathrm{gm}}\right)$.

A velocidade do vento a $10 \mathrm{~m}$ de altura é fundamental para o cálculo do índice, porém como o monitoramento da variável vento foi realizado a $1,5 \mathrm{~m}$, foi necessário aplicar um fator de escala para determinar essa variável (Equação 1) (Bröde et al., 2012):

$\mathrm{va}=\mathrm{va}_{\mathrm{xm}} \times \log \left(\frac{10}{0,01}\right) \div \log \left(\frac{\mathrm{x}}{0,01}\right)$

em que: va = velocidade do vento a $10 \mathrm{~m}$ de altura, em $\mathrm{m} / \mathrm{s} ; \mathrm{va}_{\mathrm{xm}}=$ velocidade do vento medida a $\mathrm{x}$ metros, em $\mathrm{m} / \mathrm{s} ; \mathrm{x}=$ altura na qual a velocidade do vento foi medida, neste caso a $1,5 \mathrm{~m}$.

A $\mathrm{T}_{\mathrm{gm}}$ também foi calculada. Para isso, utilizou-se a fórmula definida pela ISO 7726 (ISO, 1998) para convecção forçada (Equação 2):

$T_{r m}=\left[(t g+273)^{4}+2,5 \times 10^{8} \times v_{a}^{0,6} \times(t g-t a)\right]^{\frac{1}{4}}-273$

em que: $\mathrm{T}_{\mathrm{rm}}=$ temperatura média radiante $\left({ }^{\circ} \mathrm{C}\right)$; $\operatorname{tg}=$ temperatura do globo $\left({ }^{\circ} \mathrm{C}\right) ; v_{a}=$ velocidade do vento $(\mathrm{m} / \mathrm{s}) ; t a=$ temperatura do $\operatorname{ar}\left({ }^{\circ} \mathrm{C}\right)$.
Realizados os ajustes e demais cálculos necessários, como descritos acima, obteve-se o UTCI para cada conjunto de dados. Esses valores, além de apresentados numericamente, foram classificados em suas respectivas classes de estresse térmico, conforme a Tabela 1.

Os dados de $\mathrm{T}_{\mathrm{ar}}$ UR e índice de conforto foram processados em planilha de dados no Excel, onde foram determinadas as médias de cada ambiente e em cada estação do ano. Essas médias foram comparadas estatisticamente pelo teste $\mathrm{t}$ de Student a $1 \%$ de significância. Os valores máximos e mínimos das variáveis microclimáticas foram calculados e, assim, as máximas e mínimas encontradas no fragmento de floresta urbana e demais ambientes foram apresentadas na forma de figuras.

Realizou-se também análise das diferenças encontradas entre os ambientes. Para isso, foi preciso utilizar os dados pareados, a cada minuto, onde os valores encontrados no fragmento de floresta urbana foram subtraídos dos valores encontrados nos demais ambientes. Dessa forma obteve-se a diferença microclimática e de conforto térmico proporcionada em cada ambiente e estação do ano. Com esse conjunto de dados foi montado um delineamento estatístico em esquema fatorial $3 \times 4$ (três ambientes e quatro estações do ano) e a comparação das médias foi realizada através do teste SNK (Student-Newman-Keuls) a 1\% de significância.

Para a análise de conforto térmico, foi determinado ainda, para cada ambiente e estação do ano, o tempo

Tabela 1. Classes e nível de estresse térmico baseado no UTCI.

Table 1. Category and level of thermal stress based in UTCI.

\begin{tabular}{rc}
$\begin{array}{c}\text { Classes do } \\
\text { UTCI }\end{array}$ & Nível de estresse térmico \\
$-40{ }^{\circ} \mathrm{C}$ & Extremo estresse para o frio \\
$-27^{\circ} \mathrm{C}$ & Muito forte estresse para o frio \\
$-13^{\circ} \mathrm{C}$ & Forte estresse para o frio \\
$0{ }^{\circ} \mathrm{C}$ & Moderado estresse para o frio \\
$9{ }^{\circ} \mathrm{C}$ & Pouco estresse para o frio \\
$26{ }^{\circ} \mathrm{C}$ & Sem estresse térmico (conforto) \\
$32^{\circ} \mathrm{C}$ & Moderado estresse para o calor \\
$38^{\circ} \mathrm{C}$ & Forte estresse para o calor \\
$46{ }^{\circ} \mathrm{C}$ & Muito forte estresse para o calor \\
\hline
\end{tabular}

Fonte: Blażejczyk et al. (2010); Universal Thermal Climate Index (UTCI, 2012). 
de permanência nas classes de estresse térmico. Assim, foram elaboradas figuras para comparar o resultado encontrado no capão e os três ambientes citados anteriormente.

\section{RESULTADOS E DISCUSSÃO}

Observa-se na Tabela 2 que a análise estatística realizada demonstrou diferença significativa entre a média de temperatura do fragmento de floresta urbana e a média dos demais ambientes estudados, em todas as estações do ano. Isso ocorreu também para os valores de UR. Esses resultados refletem o benefício microclimático proporcionado pela floresta. Ocorrem devido à redução da passagem dos raios solares para o chão, proporcionando sombreamento (Mahmoud, 2011). Além disso, a evapotranspiração das plantas exerce efeito muito positivo, pois esse processo tem a capacidade de absorver calorias, o que leva à diminuição da temperatura do microclima local nas horas de maior calor (Abreu, 2008).

No estudo realizado no campus do IFMT, os menores valores de temperatura $\left(<27,4^{\circ} \mathrm{C}\right)$ e os maiores valores de umidade relativa $(>63,7 \%)$ também foram encontrados na região com vegetação, no entanto os maiores valores de temperatura foram encontrados na área de solo exposto $\left(>28,2^{\circ} \mathrm{C}\right)$ e os menores valores de umidade relativa, na área asfaltada $(<60,4 \%)$ (Machado et al., 2013).
Santos et al. (2011), ao realizar uma caracterização do campo térmico e suas relações com o uso e ocupação do solo no campus central da Universidade Federal da Paraíba (UFPB), verificou que a amenização das condições de temperatura ocorreu em função da cobertura vegetal. Nas áreas com alto adensamento de construções e solo praticamente impermeável as temperaturas foram superiores em $1{ }^{\circ} \mathrm{C}$.

Os resultados encontrados na presente pesquisa evidenciam estatisticamente a melhoria microclimática proporcionada pelo fragmento de floresta urbana, com a atenuação da temperatura e aumento da umidade relativa. Em pesquisas realizadas neste mesmo fragmento florestal, para verificar a diferença microclimática entre o interior da floresta e a área externa, Martini et al. (2011), no verão, verificaram que no interior do fragmento de floresta urbana a temperatura foi em média $5^{\circ} \mathrm{C}$ mais amena e a umidade relativa foi maior em $27,6 \%$ do que na área externa. Esses valores são mais expressivos do que os encontrados pelos autores, como Mascaró \& Mascaró (2009), Smith et al. (2011) e Armson et al. (2012), quando se referem quantitativamente ao benefício microclimático fornecido pelas áreas verdes.

A análise realizada para os valores extremos, tanto de temperatura quanto de umidade relativa, aponta esse mesmo comportamento, com o fragmento florestal apresentando maiores valores de temperatura e menores de umidade relativa (Figura 2). Esse resultado segue

Tabela 2. Média das variáveis meteorológicas e análise estatística (teste t) entre o fragmento de floresta urbana e os demais ambientes em cada estação do ano.

Table 2. Average meteorological variables and statistical analysis ( $t$ test) between the urban forest fragment and other environments in each season.

\begin{tabular}{|c|c|c|c|c|c|c|c|c|}
\hline \multirow{2}{*}{ Ambientes } & \multicolumn{4}{|c|}{ Temperatura $\left({ }^{\circ} \mathrm{C}\right)$} & \multicolumn{4}{|c|}{ Umidade relativa (\%) } \\
\hline & PRI & VER & OUT & INV & PRI & VER & OUT & INV \\
\hline Floresta urbana & 22,80 & 23,21 & 24,00 & 14,41 & 81,47 & 85,19 & 80,99 & 85,75 \\
\hline Gramado & 27,34 & 27,51 & 28,49 & 19,39 & 61,03 & 65,13 & 63,87 & 62,74 \\
\hline Teste $\mathrm{t}$ & $\begin{array}{c}13,34^{* *} \\
(\mathrm{p}<0,00)\end{array}$ & $\begin{array}{c}44,86^{* *} \\
(\mathrm{p}<0,00)\end{array}$ & $\begin{array}{c}23,31^{* *} \\
(\mathrm{p}<0,00)\end{array}$ & $\begin{array}{c}29,53^{* *} \\
(\mathrm{p}<0,00)\end{array}$ & $\begin{array}{c}13,75^{\star *} \\
(\mathrm{p}<0,00)\end{array}$ & $\begin{array}{c}55,63^{* *} \\
(\mathrm{p}<0,00)\end{array}$ & $\begin{array}{c}22,45^{* *} \\
(\mathrm{p}<0,00)\end{array}$ & $\begin{array}{c}24,73^{* *} \\
(\mathrm{p}<0,00)\end{array}$ \\
\hline Floresta urbana & 23,76 & 24,39 & 16,37 & 14,80 & 71,75 & 90,40 & 75,82 & 84,50 \\
\hline Bosque de pinus & 25,49 & 29,05 & 16,06 & 15,44 & 55,11 & 56,29 & 78,08 & 80,54 \\
\hline Teste $\mathrm{t}$ & $\begin{array}{c}13,11^{\star *} \\
(\mathrm{p}<0,00)\end{array}$ & $\begin{array}{c}45,85^{\star *} \\
(\mathrm{p}<0,00)\end{array}$ & $\begin{array}{c}2,28^{\star} \\
(p=0,02)\end{array}$ & $\begin{array}{c}9,53^{\star *} \\
(\mathrm{p}<0,00)\end{array}$ & $\begin{array}{c}26,44^{* *} \\
(\mathrm{p}<0,00)\end{array}$ & $\begin{array}{l}100,28^{\star *} \\
(\mathrm{p}<0,00)\end{array}$ & $\begin{array}{c}2,27^{\star} \\
(p=0,02)\end{array}$ & $\begin{array}{c}12,00^{* *} \\
(\mathrm{p}<0,00)\end{array}$ \\
\hline Floresta urbana & 26,76 & 27,17 & 16,03 & 16,69 & 43,29 & 59,86 & 95,20 & 83,09 \\
\hline Estacionamento & 32,30 & 30,79 & 19,70 & 20,56 & 27,73 & 51,16 & 71,09 & 70,72 \\
\hline Teste $\mathrm{t}$ & $\begin{array}{c}37,15^{\star *} \\
(\mathrm{p}<0,00)\end{array}$ & $\begin{array}{c}23,70^{\star *} \\
(\mathrm{p}<0,00)\end{array}$ & $\begin{array}{c}45,12^{* *} \\
(\mathrm{p}<0,00)\end{array}$ & $\begin{array}{c}24,91^{\star *} \\
(\mathrm{p}<0,00)\end{array}$ & $\begin{array}{c}34,21^{* *} \\
(\mathrm{p}<0,00)\end{array}$ & $\begin{array}{c}15,14^{* *} \\
(\mathrm{p}<0,00)\end{array}$ & $\begin{array}{c}60,69^{* *} \\
(\mathrm{p}<0,00)\end{array}$ & $\begin{array}{c}18,88^{\star *} \\
(\mathrm{p}<0,00)\end{array}$ \\
\hline
\end{tabular}

${ }^{*}$ Significativo a $5 \%$ de probabilidade pelo teste $t$ de Student. ${ }^{* *}$ Significativo a $1 \%$ de probabilidade pelo teste $t$ de Student. 
Temperatura máxima
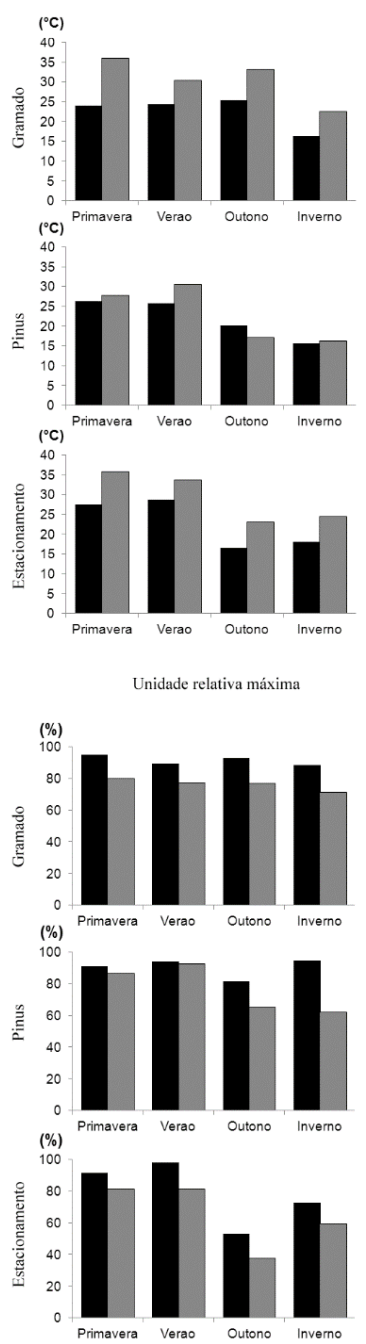

Unidade relativa máxima
Temperatura mínima

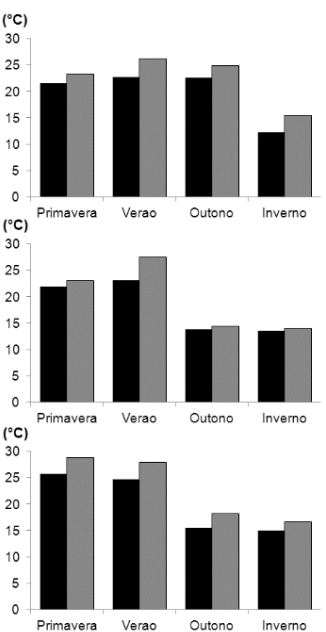

Unidade relativa mínima

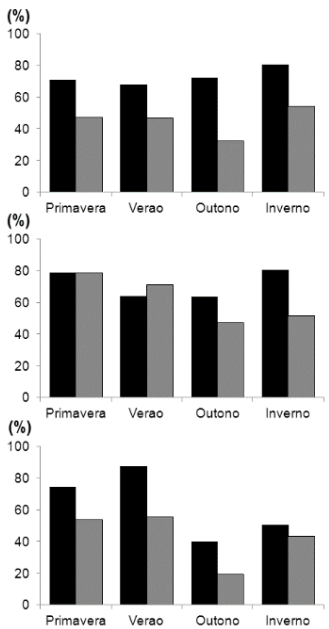

Figura 2. Valores extremos das variáveis meteorológicas encontrados no fragmento de floresta urbana e nos demais ambientes, em cada estação do ano.

Figure 2. Extreme values of meteorological variables found in the urban forest fragment and in other environments, in every season of the year.

o mesmo comportamento já descrito para os valores médios dessas variáveis, uma vez que os valores extremos contribuem para a definição das médias. Desse modo, à redução da passagem dos raios solares a superfície e a evapotranspiração proporcionada pelo fragmento florestal também contribuem para a atenuação dos extremos microclimáticos. Santos et al. (2011) também verificaram menores valores de temperaturas máximas e mínimas nas áreas com cobertura vegetal, sendo que os valores de umidade relativa foram maiores.
A Figura 2 mostra que as temperaturas máximas e mínimas sempre foram menores no interior do fragmento de floresta urbana do que nos demais ambientes estudados; em média a diferença foi de $5{ }^{\circ} \mathrm{C}$ para as máximas e $2,3{ }^{\circ} \mathrm{C}$ para as mínimas. Esse resultado não se repetiu apenas para a temperatura máxima quando comparada com o interior do bosque de pinus, na estação do outono. Destaca-se ainda que as temperaturas mínimas no fragmento de floresta urbana não foram tão baixas quando comparadas aos demais ambientes. Conforme afirmam Cruz \& Lombardo (2007), as temperaturas máximas sempre ficam mais baixas sob a vegetação e as temperaturas mínimas ficam mais elevadas em relação aos locais com pouca ou nenhuma cobertura vegetal.

Os valores de umidade relativa máxima e mínima no interior do capão foram maiores do que nos demais ambientes, em todas as estações do ano, exceto no verão, quando a umidade relativa mínima observada no interior do bosque de pinus foi maior. $\mathrm{O}$ fato de a umidade relativa mínima ter sido maior no bosque de pinus foi inesperado e pontual, pois esse comportamento não se repetiu para os valores médios e máximos e nem nas demais estações. Dessa forma, não é possível afirmar o motivo do comportamento dessa variável no bosque de pinus.

A semelhança microclimática encontrada entre o fragmento florestal e o bosque de pinus é justificável devido à semelhança de cobertura do solo - ambiente composto por um tipo de vegetação predominantemente arbórea. Essa semelhança pode ainda ser observada quando se faz uma análise geral das diferenças dos extremos microclimáticos entre os ambientes. Uma vez que a diferença dos extremos na área de gramado e estacionamento é mais acentuada com relação ao fragmento de floresta urbana do que o verificado no bosque de pinus.

Os resultados apresentados acima descrevem o microclima proporcionado pelo fragmento de floresta urbana e os demais ambientes analisados, de modo a comparar paralelamente o microclima de um lugar com o outro, utilizando os valores reais das variáveis meteorológicas coletadas em campo. No entanto, além da análise microclimática, com as variáveis meteorológicas coletadas, foi possível analisar o conforto térmico humano proporcionado pelos diferentes ambientes. Assim, ao analisar as diferenças entre os locais, com 
os valores processados de cada variável, foi possível determinar a real influência que o fragmento de floresta urbana exerce, nas quatro estações do ano, tanto em termos microclimáticos quanto de conforto térmico.

$\mathrm{A}$ análise de variância aplicada às variáveis $\mathrm{T}_{\mathrm{ar}}$, UR e índice de conforto térmico indicou diferença significativa para todas as médias encontradas entre os ambientes (fator 1) e as estações do ano (fator 2), além de interação entre esses dois fatores (Tabela 3 ).

Para a variável $\mathrm{T}_{\mathrm{ar}}$ a maior diferença média foi encontrada entre o gramado e o capão $\left(4,58{ }^{\circ} \mathrm{C}\right)$, diferenciando-se estatisticamente das demais. Embora muito semelhante, a diferença entre o estacionamento e o capão $\left(4,18^{\circ} \mathrm{C}\right)$ foi estatisticamente menos expressiva. Já a diferença entre o bosque de pinus e o fragmento de floresta urbana foi a menor entre todos os ambientes $\left(1,68^{\circ} \mathrm{C}\right)$. Novamente, esse resultado deve-se à função desempenhada pelas árvores em geral, sejam elas plantadas ou nativas. A UR seguiu esse mesmo comportamento, onde a maior diferença foi observada no gramado $(20,16 \%)$, seguido pelo estacionamento $(15,19 \%)$ e bosque de pinus $(13,12 \%)$.

Machado et al. (2013), no Campus do IFMT, encontrou a maior diferença de temperatura entre a região com vegetação e as áreas de solo exposto e a maior diferença de umidade relativa entre a região com vegetação e a área asfaltada. Alves \& Biudes (2012), no campus da UFMT, constataram a relação entre o revestimento da superfície com pavimento asfáltico e os maiores valores térmicos, bem como menores taxas higrométricas. Além disso, verificaram a importância das áreas verdes para a diminuição da temperatura do ar e para o acréscimo da umidade relativa. Segundo Soares \& Batista (2004), a umidade relativa do ar apresenta um curso diário inverso ao da temperatura do ar, isso porque a umidade relativa é inversamente proporcional à pressão de saturação de vapor d'água $\left(\mathrm{e}_{\mathrm{s}}\right)$, que por sua vez é diretamente proporcional à temperatura do ar.

Ainda com relação ao microclima, na estação do verão foi observada estatisticamente a maior diferença de $\mathrm{T}_{\mathrm{ar}}\left(4,2^{\circ} \mathrm{C}\right)$ e UR $(20,1 \%)$, seguida pela estação da primavera e inverno. Na estação do outono de um modo geral, encontrou-se a menor diferença entre os ambientes, $2,6^{\circ} \mathrm{C}$ de $\mathrm{T}_{\mathrm{ar}}$ e $13,0 \%$ de UR.

Outono e a primavera são estações de transição (Souza \& Borsato, 2011). Segundo os mesmos autores, essa variação é circunstância do sistema atmosférico que atua, o qual é variável, alternando em poucos dias. Isso pode explicar o motivo pelo qual a estação do outono apresentou as menores diferenças, uma vez que os dias escolhidos para a realização das coletas apresentaram características de inverno mais expressivas do que as observadas nos dias da estação do inverno.

Tabela 3. Diferença entre o fragmento de floresta urbana (FFU) e os ambientes com a análise estatística (SNK) das variáveis meteorológicas e do índice de conforto térmico em cada estação do ano.

Table 3. Difference between Urban Forest Fragment (FFU) and environments with statistical analysis (SNK) of meteorological variables and thermal comfort index for each season.

\begin{tabular}{|c|c|c|c|c|c|}
\hline Ambientes & Primavera & Verão & Outono & Inverno & Média \\
\hline \multicolumn{6}{|c|}{ Temperatura $\left({ }^{\circ} \mathrm{C}\right)$} \\
\hline FFU/Gramado & 4,55 & 4,30 & 4,49 & 4,98 & $4,58 \mathbf{a}$ \\
\hline FFU/Bosque de pinus & 1,72 & 4,66 & $-0,31$ & 0,63 & $1,68 \mathrm{c}$ \\
\hline FFU/Estacionamento & 5,54 & 3,62 & 3,67 & 3,87 & $4,18 \mathbf{b}$ \\
\hline Média & $3,94 \mathbf{b}$ & $4,19 \mathbf{a}$ & $2,62 \mathbf{d}$ & $3,16 \mathrm{c}$ & \\
\hline \multicolumn{6}{|c|}{ Umidade relativa (\%) } \\
\hline FFU/Gramado & 20,44 & 20,06 & 17,11 & 23,02 & $20,16 \mathbf{a}$ \\
\hline FFU/Bosque de pinus & 16,64 & 34,11 & $-2,25$ & 3,97 & $13,12 \mathrm{c}$ \\
\hline FFU/Estacionamento & 15,56 & 8,71 & 24,11 & 12,38 & $15,19 \mathbf{b}$ \\
\hline Média & 17,55 b & $20,96 \mathbf{a}$ & $12,99 \mathrm{c}$ & $13,12 \mathrm{c}$ & \\
\hline \multicolumn{6}{|c|}{ Índice de conforto térmico - UTCI $\left({ }^{\circ} \mathrm{C}\right)$} \\
\hline FFU/Gramado & 5,03 & 6,36 & 6,58 & 6,79 & $6,19 \mathbf{b}$ \\
\hline FFU/Bosque de pinus & 0,10 & 2,82 & $-2,03$ & $-0,45$ & $0,11 \mathrm{c}$ \\
\hline FFU/Estacionamento & 8,77 & 5,16 & 6,40 & 6,75 & $6,77 \mathbf{a}$ \\
\hline Média & $4,63 \mathbf{a b}$ & $4,78 \mathbf{a}$ & $3,65 \mathrm{c}$ & $4,37 \mathbf{b}$ & \\
\hline
\end{tabular}

Médias seguidas de mesma letra na coluna ou na linha não diferem entre si a 1\% de significância pelo teste SNK. 
Os resultados encontrados no verão condizem com Mascaró \& Mascaró (2009), onde afirmam que as maiores diferenças são verificadas nessa estação, pois esse efeito é proporcional à densidade foliar da vegetação. Dessa forma, no verão, a temperatura das áreas vegetadas tem efeito mais forte de resfriamento do que no inverno (Chang et al., 2007). Inclusive, Akbari \& Taha (1992) alertam que a falta de vegetação causa a diminuição da temperatura no inverno, devido à facilidade com que os materiais de construção perdem calor para o meio, onde não existem barreiras naturais para detê-lo.

Sendo assim pode-se afirmar que o fragmento florestal exerce influência significativa sobre as variáveis meteorológicas que compõem o microclima local, pois foi constatado que os demais ambientes analisados apresentaram condições microclimáticas diferentes do observado no interior do fragmento de floresta urbana, com maiores valores de temperatura do ar e menores valores de umidade relativa, em todas as estações do ano. Em estudos similares em outras localidades do país, de condições climáticas distintas, pesquisadores também encontraram resultados semelhantes. Machado et al. (2013), no campus Cuiabá (Bela Vista) do Instituto Federal de Mato Grosso (IFMT), constatou que as áreas cobertas por vegetação tiveram menores valores de temperatura e maiores valores de umidade relativa, enquanto as áreas sem cobertura vegetal tiveram padrão inverso. Na Universidade Federal de Mato
Grosso (UFMT), também em Cuiabá, Alves \& Biudes (2011) comprovaram que existe uma relação entre os tipos de uso e ocupação do solo sobre a temperatura e umidade relativa do ar, onde as áreas com vegetação proporcionam melhores condições microclimáticas.

O conforto térmico também foi analisado separadamente para cada ambiente e estação do ano (Tabela 4). Verificou-se que todos os ambientes apresentaram condições de conforto térmico diferentes do observado no interior do fragmento de floresta urbana. De modo geral, nos ambientes estudados foram encontrados os maiores valores do índice de conforto.

Observa-se, na Tabela 4, que em todas as estações do ano houve diferenças significativas entre as médias do índice de conforto térmico do fragmento de floresta urbana e as médias dos demais ambientes estudados. No entanto, embora exista essa diferença estatística, em muitas situações a classe de conforto foi similar entre os locais. Isso ocorre porque a análise estatística se respalda apenas no número em si e o índice de conforto leva em conta diversos fatores como, por exemplo, pessoais, psicológicos e subjetivos, o que permite que um valor numérico possa significar o mesmo que outro valor.

Em todas as estações a classe de conforto térmico encontrada para o fragmento de floresta urbana foi igual ao bosque de pinus. Refletindo o que já era esperado, devido à abordagem realizada para o microclima,

Tabela 4. Média dos valores do UTCI e análise estatística (teste t) entre o capão e os demais ambientes em cada estação do ano.

Table 4. Average values of UTCI and statistical analysis ( $t$ test) between the urban forest fragment and other environments in each season.

\begin{tabular}{|c|c|c|c|c|}
\hline Ambiente & Primavera & Verão & Outono & Inverno \\
\hline Fragmento de floresta urbana & 25,0 & 25,6 & 26,2 & 16,1 \\
\hline Gramado & 30,0 & 32,0 & 32,8 & 22,9 \\
\hline test $\mathrm{t}$ & $\begin{array}{c}10,4^{\star *} \\
(\mathrm{p}<0,00)\end{array}$ & $\begin{array}{c}56,1^{\star *} \\
(\mathrm{p}<0,00)\end{array}$ & $\begin{array}{c}27,5^{\star *} \\
(\mathrm{p}<0,00)\end{array}$ & $\begin{array}{c}60,6^{* *} \\
(p<0,00)\end{array}$ \\
\hline Fragmento de floresta urbana & 25,8 & 27,6 & 19,1 & 16,8 \\
\hline Bosque de pinus & 25,9 & 30,4 & 17,1 & 16,4 \\
\hline test $\mathrm{t}$ & $\begin{array}{r}0,6^{* *} \\
(\mathrm{p}<0,00)\end{array}$ & $\begin{array}{r}29,2^{* *} \\
(p<0,00)\end{array}$ & $\begin{array}{c}10,22^{\star *} \\
(\mathrm{p}<0,00)\end{array}$ & $\begin{array}{r}3,7^{* *} \\
(\mathrm{p}<0,00)\end{array}$ \\
\hline Fragmento de floresta urbana & 26,5 & 28,2 & 18,3 & 18,6 \\
\hline Estacionamento & 35,2 & 33,3 & 24,6 & 25,3 \\
\hline test $\mathrm{t}$ & $\begin{array}{c}70,8^{\star *} \\
(\mathrm{p}<0,00)\end{array}$ & $\begin{array}{c}17,9^{* *} \\
(\mathrm{p}<0,00)\end{array}$ & $\begin{array}{c}48,1^{* *} \\
(\mathrm{p}<0,00)\end{array}$ & $\begin{array}{r}41,9^{* *} \\
(\mathrm{p}<0,00)\end{array}$ \\
\hline
\end{tabular}

LEGENDA: Sem estresse Moderado calor Forte calor Muito forte calor Extremo calor

** Significativo a $1 \%$ de probabilidade pelo teste t de Student. 
uma vez que também se trata de um ambiente com espécies arbóreas.

$\mathrm{Na}$ estação do inverno todos os ambientes apresentaram conforto térmico, o que é um resultado importante, pois no inverno há um consenso popular de que ficar no sol é mais agradável para se proteger do frio, assim imagina-se que estar em uma floresta pode ser mais desconfortável, por não ter a incidência direta de raios solares, assim com base neste estudo pode se afirmar que mesmo no inverno a floresta proporciona condições de conforto térmico.

Nas demais estações, o gramado e o estacionamento apresentaram maior desconforto do que o fragmento de floresta urbana. Esse resultado se explica principalmente pela incidência direta de raios solares na superfície, devido à falta de barreira, o que promove maior aquecimento. Além disso, a cobertura do solo também contribui para esse aquecimento, o gramado embora seja uma forma de vegetação possui elevado valor de refletância.
Com base nesses valores do índice de conforto, foi possível verificar claramente que o fragmento de floresta urbana proporciona melhores condições de conforto térmico. Em algumas ocasiões, embora também tenha sido classificado como desconfortável, a classe de desconforto (moderado calor) foi inferior à proporcionada pelos demais ambientes (forte calor).

Os resultados apresentados acima se referem aos valores médios encontrados durante todo o período de análise, para cada dia de coleta. No entanto, se fez necessário, ainda, realizar uma análise do tempo de permanência nas classes de conforto térmico dos ambientes, para determinar em cada dia o período em que o ambiente apresentou conforto ou desconforto térmico, uma vez que a média poderia não refletir a real situação. A partir dessa análise também foi possível constatar o benefício proporcionado pelo fragmento de floresta urbana (Figura 3). De modo geral, o tempo de permanência na classe de conforto térmico foi maior no fragmento de floresta urbana do que nos demais ambientes.

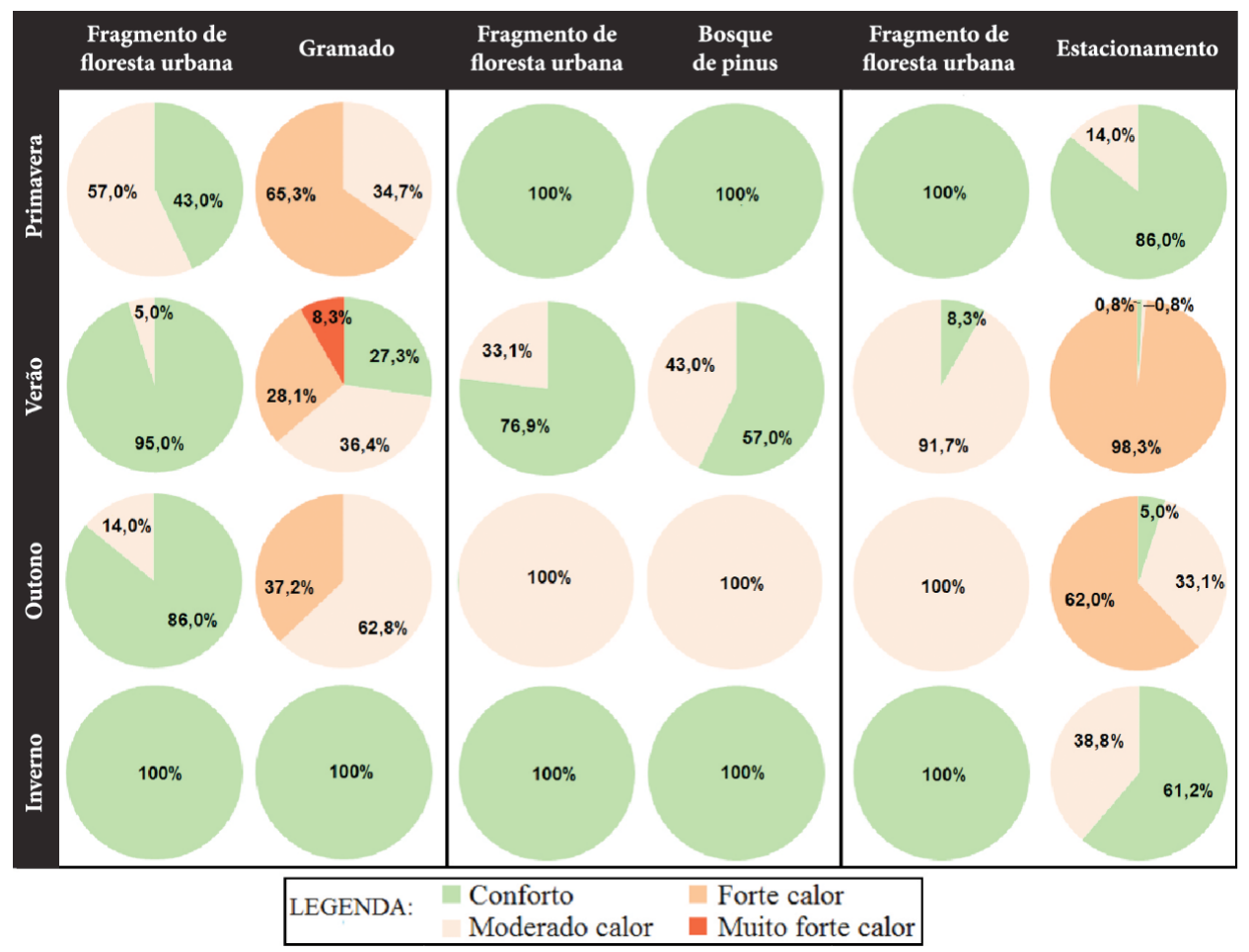

Figura 3. Tempo de permanência em cada classe de estresse térmico do fragmento de floresta urbana e dos demais ambientes nas quatro estações do ano.

Figure 3. Duration of stay in each class of thermal stress of the urban forest fragment and other environments in four seasons. 
A Figura 3 compara o fragmento de floresta com os demais ambientes quanto ao tempo que permaneceram em cada classe de conforto, nas quatro estações do ano. Com relação ao primeiro ambiente apresentado, o gramado, é possível observar que este não apresentou conforto térmico (cor verde) em nenhum momento durante a primavera e outono, enquanto que o fragmento de floresta urbana apresentou conforto em $43 \%$ do tempo na primavera e $88 \%$ no outono. Na estação do verão, durante $95 \%$ do tempo, o fragmento de floresta urbana apresentou conforto térmico, enquanto que no gramado isso ocorreu em apenas $27,3 \%$ do tempo $(67,7 \%$ menor). No inverno, observa-se que os dois locais apresentaram conforto durante todo o período de coleta. Martini et al. (2011) já haviam encontrado melhores condições de conforto térmico no interior desse fragmento do que na área externa com gramado.

O bosque de pinus foi o ambiente que mais se assemelhou ao fragmento de floresta urbana com relação ao conforto térmico; na primavera e inverno, os dois ambientes apresentaram conforto durante todo o período de análise. No outono, os dois locais apresentaram desconforto por "moderado calor" durante todo o período. Verão foi a única estação em que houve distinção entre os ambientes; o tempo de permanência na classe de conforto do fragmento de floresta foi de $76,9 \%$ enquanto que do bosque de pinus este tempo foi de 57\% (19,9\% menor).

$\mathrm{O}$ estacionamento foi o ambiente que mais se diferenciou do fragmento de floresta urbana. O tempo de permanência na classe de conforto no fragmento de floresta urbana foi de $100 \%$ na primavera, $8,3 \%$ no verão e $100 \%$ no outono, enquanto que do estacionamento foi respectivamente: $86 \%, 0,8 \%, 5 \%$ e $61,2 \%$. Na estação do verão os dois ambientes apresentaram desconforto durante a maior parte do tempo, no entanto, o desconforto observado no fragmento de floresta urbana foi por "moderado calor" (em 91,7\% do tempo) enquanto que do estacionamento foi por "forte calor" (em 98,3\% do tempo). No outono, durante todo o tempo, o fragmento de floresta apresentou desconforto por "moderado calor", no entanto esse desconforto foi menor do que o observado no estacionamento, pois em $62 \%$ do tempo esse local apresentou desconforto por "forte calor".

Com a análise desses resultados, confirma-se que o fragmento de floresta urbana proporciona melhores condições de conforto térmico do que os demais ambientes.
Isso pode ser verificado tanto quando se analisam os valores médios ao longo de todo o período de coleta como quando se analisa o tempo de permanência em cada classe de conforto e desconforto térmico.

$\mathrm{Na}$ análise do conforto térmico, pode-se observar o mesmo comportamento apontado para o microclima, com relação às estações do ano. Na estação do verão, observou-se a maior diferença de conforto térmico entre os ambientes e no outono a menor, ambas comprovadas estatisticamente. Já na análise dos ambientes, verificou-se que o estacionamento proporciona a maior diferença com relação ao fragmento de floresta urbana, seguido pelo gramado e o bosque de pinus. Parece ser um resultado satisfatório, pois indica que, mesmo apresentando menores valores de temperatura do que a área com gramado, o estacionamento apresenta maior desconforto.

Silva et al. (2011), por meio do índice de Thom, também verificaram que a área mais confortável do campus da UFPB foi a que apresentou considerável cobertura arbórea. No entanto, na UFPB, a área menos confortável foi de um local cujo solo é recoberto por areia, junto a uma rua com pavimentação asfáltica.

\section{CONCLUSÃO}

O fragmento de floresta urbana localizado no campus III da Universidade Federal do Paraná proporciona microclimas mais confortáveis termicamente do que os demais ambientes analisados (gramado, bosque de pinus e estacionamento), com menores valores de temperatura e maiores valores de umidade relativa.

Em todas as estações do ano foi possível quantificar e comprovar estatisticamente a influência da vegetação nas variáveis meteorológicas e no índice de conforto térmico. Para a variável temperatura, a maior diferença média dos ambientes é encontrada entre o fragmento de floresta urbana e o gramado, seguida pelo estacionamento e o bosque de pinus. A umidade relativa seguiu essa mesma linha.

O estacionamento é o ambiente que proporciona maior desconforto térmico quando comparado ao fragmento de floresta urbana, seguido pelo gramado. Enquanto o bosque de pinus, em todas as estações do ano apresenta a mesma classe de conforto térmico que o fragmento de floresta urbana, conforto na primavera, 
verão e inverno e desconforto por "moderado calor" no outono.

Os resultados encontrados enfatizam a importância da conservação e manutenção dos fragmentos de floresta urbana, pois proporcionam melhores condições de conforto térmico, contribuindo para a melhoria da qualidade de vida.

\section{STATUS DA SUBMISSÃO}

Recebido: 13 mar., 2014

Aceito: 17 fev., 2015

\section{AUTOR(ES) PARA CORRESPONDÊNCIA}

\section{Angeline Martini}

Departamento de Ciências Florestais, Universidade Federal do Paraná - UFPR, Av. Pref. Lothário Meissner, 632, Jardim Botânico, CEP 80210-170, Curitiba, PR, Brasil

e-mail: martini.angeline@gmail.com

\section{REFERÊNCIAS}

Abreu LV. Avaliação da escala de influência da vegetação no microclima por diferentes espécies arbóreas [dissertação]. Campinas: Faculdade de Engenharia Civil, Universidade Estadual de Campinas; 2008.

Akbari H, Taha H. Impact of trees and white surfaces on residential heating and cooling energy use in four Canadian cities. Energy 1992; 17(2): 141-149. http:// dx.doi.org/10.1016/0360-5442(92)90063-6.

Alves EDL, Biudes MS. Os microclimas da Universidade Federal de Mato Grosso/Cuiabá. Ra'e Ga: O Espaço Geográfico em Análise 2011; 23(0): 600-620. http://dx.doi. org/10.5380/raega.v23i0.24923.

Alves EDL, Biudes MS. Padrões da temperatura do ar e da umidade relativa: estudo de caso no Campus de Cuiabá da Universidade Federal de Mato Grosso. Boletim Geografico 2012; 30(3): 5-16.

Amorim MCCT. Climatologia e gestão do espaço urbano. Revista Mercator 2010; No espec: 71-90.

Armson D, Stringer P, Ennos AR. The effect of tree shade and grass on surface and globe temperatures in an urban area. Urban Forestry \& Urban Greening 2012; 11(3): 245255. http://dx.doi.org/10.1016/j.ufug.2012.05.002.

Beltrame MB, Moura GRS. Edificações escolares: infraestrutura necessária ao processo de ensino e aprendizagem escolar. Toledo: UNIOESTE. [cited 2011 fev. 8]. Available from: http://www.unioeste.br/prppg/mestrados/letras/ revistas/travessias/ed_006/EDUCA\%C7AO/PDF/ EDIFICA\%C7\%D5ES\%20ESCOLARES.pdf.

Biondi D. Arborização urbana: aplicada à educação ambiental nas escolas. Curitiba: O Autor; 2008.

Blażejczyk K, Broede P, Fiala D, Havenith G, Holmér I, Jendritzky G et al. Principles of the new Universal Thermal Climate Index (UTCI) and its application to bioclimatic research in European scale. Miscellanea Geographica 2010; 14: 91-102.

Bröde P, Krüger EL, Rossi FA, Fiala D. Predicting urban outdoor thermal comfort by the Universal Thermal Climate Index UTCI--a case study in Southern Brazil. International Journal of Biometeorology 2012; 56(3): 471-480. http:// dx.doi.org/10.1007/s00484-011-0452-3. PMid:21604151.

Chang C, Li M, Chang S. A preliminary study on the local cool-island intensity of Taipei city parks. Landscape and Urban Planning 2007; 80(4): 386-395. http://dx.doi. org/10.1016/j.landurbplan.2006.09.005.

Cruz GCF, Lombardo MA. A importância da arborização para o clima urbano. In: II Seminário Nacional sobre Regeneração Ambiental de Cidades; 2007; Londrina. Londrina: [publisher unknown]; 2007.

Cruz GCF. Clima Urbano de Ponta Grossa - PR: uma abordagem da dinâmica climática em cidade média subtropical brasileira [tese]. São Paulo: Faculdade de Filosofia, Letras e Ciências Humanas, Universidade de São Paulo; 2009.

Dacanal C, Labaki LC, Silva TML. Vamos passear na floresta! O conforto térmico em fragmentos florestais urbanos. Ambiente Construído 2010; 10(2): 115-132. http://dx.doi.org/10.1590/S1678-86212010000200008.

França MS. Microclimas e suas relações com o uso do solo no entorno de escolas públicas na cidade de Cuiabá/MT. Revista Educação. Cultura e Scuola 2012; 2(2): 148-161.

Gheno EL, França MS, Maitelli SF. Variações microclimáticas na área urbana de Sinop no final da estação chuvosa. Revista Educação. Cultura e Scuola 2012; 2(1): 139-153.

Instituto de Pesquisa e Planejamento Urbano de Curitiba - IPPUC. Desenvolvimento sustentável: indicadores de sustentabilidade de Curitiba - 2010. Curitiba; 2011.

Instituto de Pesquisa e Planejamento Urbano de Curitiba IPPUC. Curitiba em Dados. Curitiba. [cited 2013 jan. 17]. Available from: http://www.ippuc.org.br/Bancodedados/ Curitibaem dados/Curitiba_em_dados_Pesquisa.htm.

Instytut Geografii i Przestrzennego Zagospodarowania - IGPZ. Bioklima. [cited 2012 july 18]. Available from: http://www.igipz.pan.pl/Bioklima-zgik.html.

Internacional Organization for Stardardization - ISO. ISO 7726: ergonomics of the thermal environment: instruments of measuring physycal quantities. Switzerland; 1998. 
International Society of Biometeorology - ISB. Commission 6 for the Development of a Universal Thermal Climate Index (UTCI). Genebra: ISB Commission 6; 2003.

Leal L, Pedrosa-Macedo JH, Biondi D. Censo da arborização do Campus III - Centro Politécnico da Universidade Federal do Paraná. Scientia Agraria 2009; 10(6): 443-453. http://dx.doi.org/10.5380/rsa.v10i6.15718.

Leal L. A influência da vegetação no clima urbano da cidade de Curitiba - PR [tese]. Curitiba: Universidade Federal do Paraná; 2012.

Lima EM No. Aplicação do sistema de informações geográficas para o inventário da arborização de ruas de Curitiba, $P R$ [dissertação]. Curitiba: Universidade Federal do Paraná; 2011.

Lombardo MA. Ilha de Calor nas Metrópoles: o exemplo de São Paulo. São Paulo: Hucitec; 1985.

Machado NG, Friedlander VA, Sanches L, Biudes MS. Temperatura e umidade relativa do ar na estação seca em diferentes usos do solo no Campus Cuiabá - Bela Vista do IFMT. Revista Eletrônica em Gestão, Educação e Tecnologia Ambiental 2013; 9(9): 2018-2025.

Mahmoud AHA. Analysis of the microclimatic and human comfort conditions in an urban park in hot and arid regions. Building and Environment 2011; 46: 2641-2656.

Martini A, Biondi D, Batista AC, Lima EM No. Microclima e conforto térmico de um fragmento florestal na cidade de Curitiba-PR, Brasil. In: V Congreso Forestal Latinoamericano; 2011; Lima. Lima: [publisher unknown]; 2011.

Mascaró L, Mascaró JJ. Ambiência urbana. 3rd ed. Porto Alegre: +4; 2009.
Reis CS, Conceição GM. Aspectos florísticos de um fragmento de vegetação, localizado no Município de Caxias, Maranhão, Brasil. Scientia Plena 2010; 6(2): 2-17.

Roderjan CV, Galvão F, Kuniyoshi YS, Hatschbach GG. As unidades fitogeográficas do Estado do Paraná. Ciência \& Ambiente 2002; 24: 75-92.

Rondon RM No, Kozera C, Andrade RR, Cecy AT, Hummes AP, Fritzsons E et al. Caracterização florística e estrutural de um fragmento de Floresta Ombrófila Mista, em Curitiba, PR - Brasil. Floresta 2002; 32(1): 3-16.

Santos JS, Melo BCB, Araújo LE, Melo EEC. Caracterização do campo térmico urbano e suas relações com o uso e ocupação do solo no Campus Central da UFPB. Revista Brasileira de Geografia Física 2011; 3: 445-462.

Silva IM, Gonzalez LR, Silva DF Fo. Recursos naturais de conforto térmico: um enfoque urbano. Revista da Sociedade Brasileira de Arborização Urbana 2011; 6(4): 35-50.

Smith CL, Webb A, Levermore GJ, Lindley SJ, Beswick K. Fine-scale spatial temperature patterns across a UK conurbation. Climatic Change 2011; 109(3-4): 269-286. http://dx.doi.org/10.1007/s10584-011-0021-0.

Soares RV, Batista AC. Meteorologia e climatologia florestal. Curitiba: FUPEF; 2004.

Souza YL, Borsato VA. O índice de conforto térmico na primavera de 2009 em Campo Mourão. In: VI Encontro de Produção Científica e Tecnológica; 2011; Campo Mourão, PR. Campo Mourão: FECILCAM; 2011.

Universal Thermal Climate Index - UTCI. Documents: assessment scale. [cited 2012 may 15]. Available from: http://www.utci.org/index.php. 